Vol. XXIII, No. 1

\title{
Wild Black Currant
}

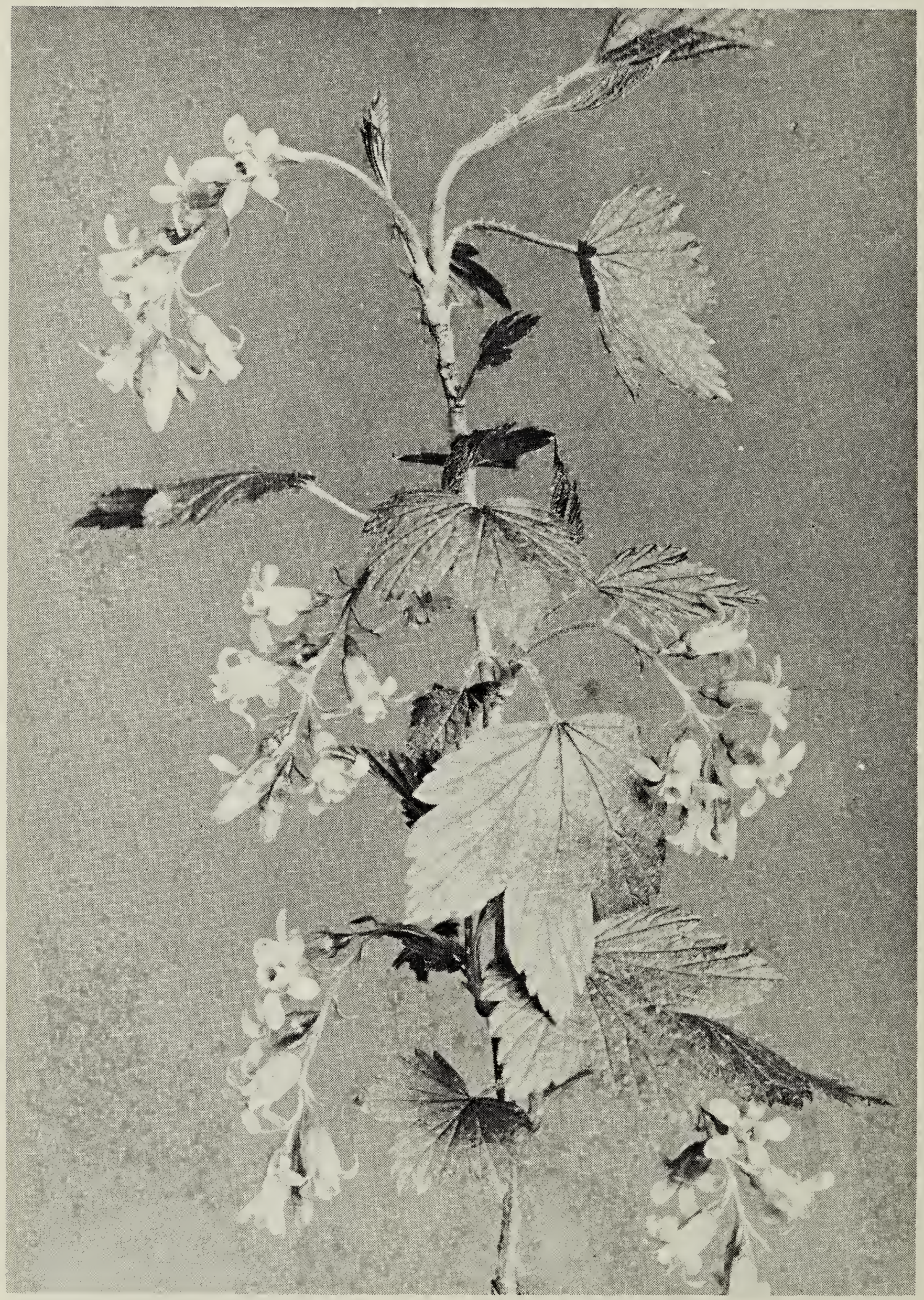

Photo by the late Dr. W. C. McCalla

Ribes americanum Mill.

The Wild Black Currant is common among thickets in rich alluvial river valleys throughout the southern half of the three prairie provinces. The greenishwhite or yellowish flowers may be seen in late May and early June. The fruit, on drooping racemes, is black. 